\title{
Stabilization Mechanism of Colloidal Suspensions by Gum Tragacanth: The Influence of $\mathrm{pH}$ on Stability
}

\author{
A. YOKOYAMA, K. R. SRINIVASAN, AND H. S. FOGLER \\ Department of Chemical Engineering, The University of Michigan, Ann Arbor, Michigan 48109
}

Received May 11, 1987; accepted February 4, 1988

\begin{abstract}
An acidic polyelectrolyte, gum tragacanth (GT), was found to stabilize polystyrene latex particles due to a steric stabilization mechanism. The stability depends significantly on the $\mathrm{pH}$ of the solution. To elucidate the stabilization mechanism, a number of parameters, such as the adsorption isotherm, the zeta potential, and the conformation were measured as a function of $\mathrm{pH}$. The adsorption isotherms showed that $\mathrm{pH}$ has little effect on the amount of GT adsorbed on the surface. Photon correlation spectroscopy studies showed that the steric layer thickness increases as $\mathrm{pH}$ decreases, demonstrating that the $\mathrm{pH}$ dependence of stability is attributed to the conformational change of GT with pH. Finally, the degree of dissociation of carboxyl groups of GT molecules (i.e., pH) has a significant effect on the flocculation behavior of latex particles and can be modulated to bring about spontaneous deflocculation of latex particles. (c) 1988 Academic Press, Inc.
\end{abstract}

\section{INTRODUCTION}

Recently, there has been a significant interest in the use of hydrocolloids to stabilize colloidal dispersions ranging from food stuffs to coal-water slurries (1). Some hydrocolloids have the advantage that they can stabilize the colloidal system even at relatively low concentrations in the order of $10 \mathrm{ppm}$. Recently, it has been shown that a complex formulation containing xanthan gum (an acidic polysaccharide) as a key component was sufficient to prevent cake formation of a $60 \mathrm{wt} \%$ coal-water slurry (2). While there was no indication of how the coal particle interacts, an explanation of the mechanism may be suggested from our previous work on the stabilization of polystyrene latices by acidic and nonionic polysaccharides such as gum tragacanth (GT), pectic acid, arabinogalactan, and dextran (3).

Gum tragacanth was found to be quite an effective stabilizer at concentration in low ppm range, and this was suggestive of a possible steric stabilization mechanism. Gum tragacanth is a dried gummy exudation of Astragalus (family of Leguminosae) and an acidic polysaccharide containing D-galacturonic acid
(4). As a natural product, it is polydisperse, and has been used as a dispersing agent, an emulsifier, and a coagulant in food industry (5).

Previous workers have used natural polymers and polyelectrolytes such as lignin sulphonates for similar studies (6) and since sulphonates are strong acids, the ionic strength of the medium was the sole property that could be adjusted to change the amount of charge of these polyelectrolytes as a means of controlling stability. Gum tragacanth, on the other hand, has weakly dissociating surface acidic groups, and solution $\mathrm{pH}$ was thought of as an ideal way to vary the amount of charge of GT and to monitor the effect of such variations on the stability of polystyrene latices.

Therefore, as a result of these preliminary findings, a detailed study of the factors bringing about the stability was undertaken. As a first step in the systematic investigation of the stabilization mechanism of GT, the effect of $\mathrm{pH}$ on stability was studied. The amount of GT adsorbed, electrostatic repulsive force, and the conformation were measured as a function of $\mathrm{pH}$. Photon correlation spectroscopy (PCS) was used to measure the steric layer thickness. 


\section{EXPERIMENTAL}

\subsection{Materials}

The monodisperse polystyrene latex (diameter: $0.33 \mu \mathrm{m}$ ) was prepared through a surfactant free procedure. Gum tragacanth and poly (galacturonic acid), PGUA, were purchased from Sigma Chemical Company. The chemical structures of GT and PGUA are shown in Figs. 1 and 2. Over half of carboxyl groups of GT are known to be esterified (7).

GT is based on poly (galacturonic acid) which is a linear chain of 1,4 linked $\alpha$-D-galacturonic acid. Three types of side chains are known, namely, single $\beta$-D-xylopyranose, and disaccharide units of 2-O- $\alpha$-L-fucopyranosylD-xylopyranose and $2-O-\beta$-D-galactopyranosyl-D-xylopyranose (8). The GT solution was prepared by first dissolving weighed GT in the sodium chloride solution $(0.085 M)$ then filtering it to remove any aggregates. The molecular weight distribution of GT was obtained by gel permeation chromatography using Sepharose 4B/CL-4B (Pharmacia Inc.) as a gel with the ionic strength of $0.085 \mathrm{M}$ at $\mathrm{pH}$ 7.4 (Table I). The polydispersity of GT and PGUA was calculated to be 2.7 .

Graten et al. (9) showed that GT molecules are thread-like and calculated the values for the ellipsoidal axes of revolution for GT of 450 and $1.9 \mathrm{~nm}$.

\subsection{Measurement of Flocculation Rate Constant}

The flocculation rate was measured by a turbidimetric technique (10). Polystyrene latex spheres $(0.33 \mu \mathrm{m})$ of the volume fraction of $2.6 \times 10^{-5}$ were incubated for 1 day in the GT solution with the ionic strength of 0.085 $M$ at $293 \mathrm{~K}$. After the incubation, the ionic strength was increased from 0.085 to $0.33 \mathrm{M}$ by the addition of magnesium chloride solution to induce flocculation. The turbidity was measured as a function of time at the wavelength of $500 \mathrm{~nm}$ with a DMS spectrophotometer Model 200 (Varian Inc.). This incubation time ( 1 day) was found to be sufficient since the dimensionless stability factor, $W$, given as Eq. [1] remained the same after an incubation time of $30 \mathrm{~min}$ or longer:

$$
W=k_{\text {without GT }} / k_{\text {with GT }} \text {. }
$$

The flocculation rate constant was obtained from the slope of the initial $2 \mathrm{~min}$ of the timeturbidity curve, and the dimensionless stability factor, $W$, was then calculated from Eq. [1]. The complete details have been described elsewhere (10).

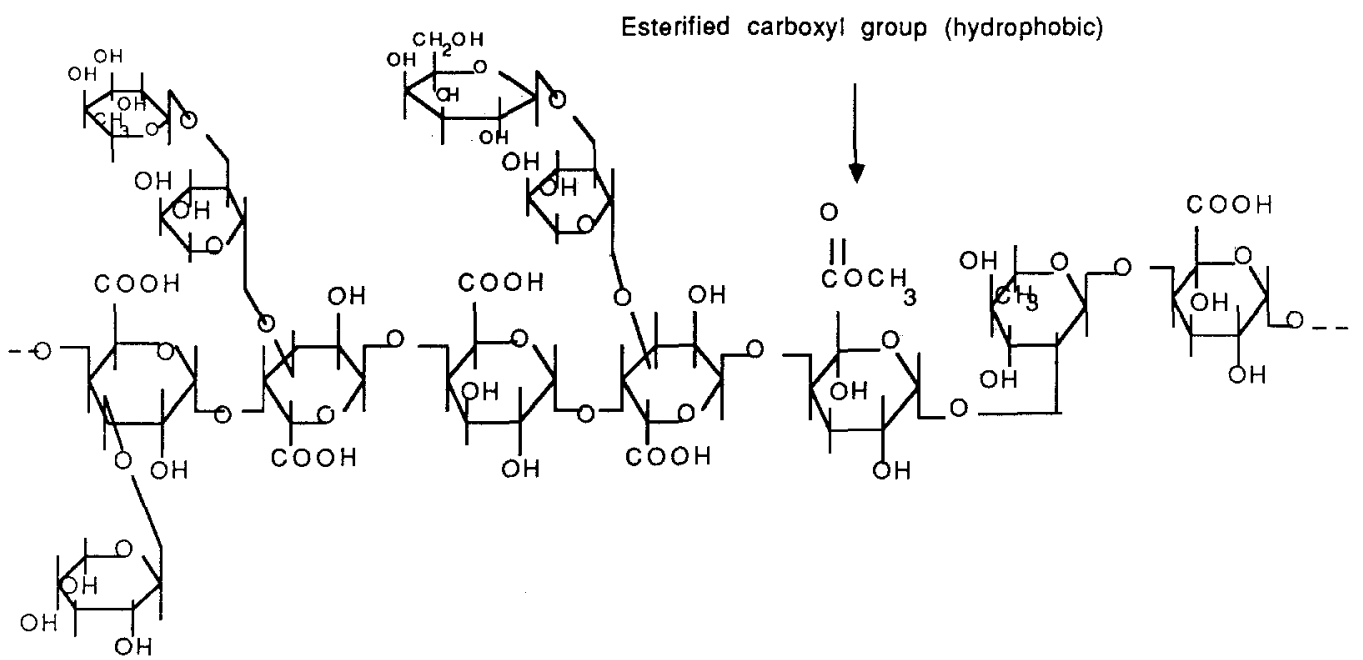

FIG. 1. Chemical structure of GT. 


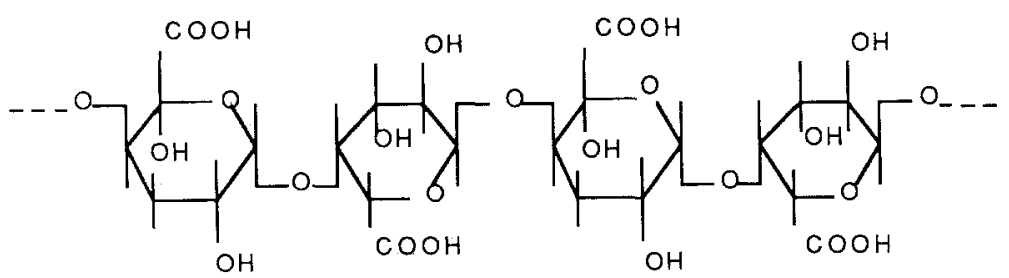

FIG. 2. Chemical structure of poly (galacturonic acid).

The $\mathrm{pH}$ was adjusted with acetic acid-sodium acetate buffer for $\mathrm{pH} 3.4$ and 5.1, while a phosphate buffer was used for $\mathrm{pH} 7.4$. The ionic strength was kept constant for different $\mathrm{pH}$ solutions by adding the appropriate amounts of sodium chloride.

\subsection{Binding Studies}

Adsorption isotherms for the binding of GT to polystyrene latex spheres were obtained for different $\mathrm{pH}$ solutions. This was achieved by first mixing GT and latex spheres for 1 day at $293 \mathrm{~K}$ followed by centrifugation at $11500 \mathrm{rpm}$ for $30 \mathrm{~min}$. The ionic strength was adjusted by adding sodium chloride. The concentration of GT in the solution was measured by phenolsulfuric acid method (11).

\subsection{Electrophoresis Measurements}

The electrophoretic mobility was determined at $293 \mathrm{~K}$ with a Lazer-Zee Model 500 (Pen Kem Inc.). Since the value for $\kappa a$ is 330 ( $\kappa$, reciprocal of double layer thickness; $a$, particle diameter), the zeta potential was calculated using the Smoluchowski equation,

\section{TABLE I}

Molecular Weight Distribution of GT Samples as Determined by GPC

\begin{tabular}{ll}
\hline Molecular weight range & $W_{\mathrm{t} \%}$ \\
\hline 6000,000 & 25.3 \\
$600,000-500,000$ & 21.7 \\
$500,000-170,000$ & 27.1 \\
$170,000-60,000$ & 12.5 \\
$<60,000$ & 13.5 \\
\hline
\end{tabular}

$$
u=\epsilon \zeta / 4 \pi \eta,
$$

where $u$ is the mobility, $\epsilon$ the dielectric constant, $\zeta$ the zeta potential, and $\eta$ the viscosity of the medium.

\section{5. $p K$ Measurement}

GT was converted into its $\mathrm{H}$-form by cation exchanger (Amberlite IRA-118H, Sigma Chemical Company) and its $\mathrm{p} K$ was measured by potentiometric titration at a constant ionic strength of $0.33 \mathrm{M}$.

\subsection{Measurement of Steric Layer Thickness by Photon Correlation Spectroscopy (PCS)}

PCS data were obtained using Lexel $2 \mathrm{~W}$ Argon ion laser with an ITT FW-130 photo multiplier tube. The different angles $\left(50^{\circ}-\right.$ $\left.100^{\circ}\right)$ and volume fractions of latex particles $\left(0-1.9 \times 10^{-6}\right)$ were employed to confirm that there is no effect of dust or particle-particle interactions. The steric layer thickness was then calculated as the difference in the radii of the bare and covered particles obtained from the diffusion coefficient using the Stokes-Einstein relation.

\section{RESULTS AND DISCUSSION}

\subsection{Effect of $p H$ on Colloidal Stabilization with $G T$}

The dimensionless stability factor, $W$, was measured as a function of GT concentration for different $\mathrm{pH}$ solutions. Figure 3 shows that the stability increases greatly as the $\mathrm{pH}$ decreases.

To find the degree of dissociation of carboxylic acid in GT at various $\mathrm{pH}$ and to study 


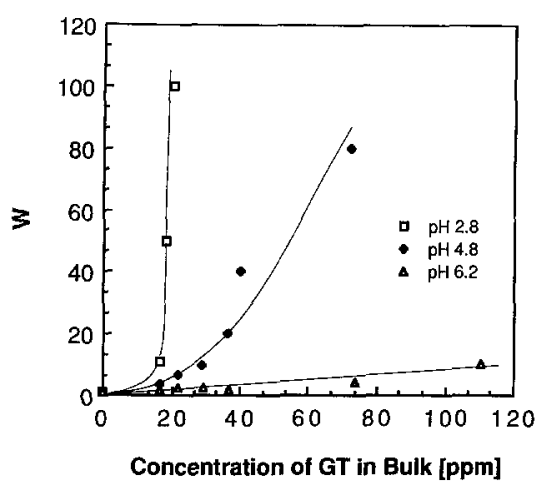

FIG. 3. Effect of pH on stabilization by GT $(0.33 \mu \mathrm{m}-$ latex: volume fraction $=2.6 \times 10^{-5}, \mathrm{MgCl}_{2}$ as flocculant; ionic strength: $0.33 \mathrm{M}$ ).

the proton-dissociation behavior of GT, the values for $\mathrm{p} K_{\mathrm{a}}$ and $n$ were measured at the same ionic strength used in flocculation measurements. The value for $n$ represents the interaction between $\mathrm{COO}^{-}$groups in one GT molecule in the Henderson-Hasselbach equation

$$
\mathrm{pH}=\mathrm{p} K_{\mathrm{a}}+n \log \{a /(1-a)\}
$$

where

$a$ : degree of dissociation,

$\mathrm{p} K_{\mathrm{a}}$ : apparent value of $\mathrm{p} K$, groups.

$n$ : constant for interaction of $\mathrm{COO}^{-}$

The results were shown in Table II.

The $\mathrm{p} K_{\mathrm{a}}$ for GT was found to be 3.0 and corresponds to an apparent degree of dissociation, $a=0.5$. This $\mathrm{p} K_{\mathrm{a}}$ value is comparable to that for poly (galacturonic acid), which was found to be 2.9. The value for $n$ of GT is also the same as that of poly (galacturonic acid) which is 1.5 . Consequently one can consider

TABLE II

$\mathrm{p} K_{\mathrm{a}}$ and $n$ for GT and Poly (Galacturonic Acid)

\begin{tabular}{lll}
\hline & $\mathrm{p} K_{\mathrm{a}}$ & $n$ \\
\hline GT & 3.0 & 1.5 \\
Poly (galacturonic acid) & 2.9 & 1.5 \\
\hline
\end{tabular}

Journal of Colloid and Interface Science. Vol. 126, No. 1, November 1988 that proton-dissociation behavior of GT is the same as that of poly (galacturonic acid). This similar proton-dissociation behavior of GT and PGUA can also be suggested by the similar effect of $\mathrm{pH}$ on the stability for PGUA as shown in Fig. 4.

There are three main possibilities for the variation in the dimensionless stability factor with $\mathrm{pH}$ at the same concentration of GT in bulk: (A) the amount of GT adsorbed on particles varies with $\mathrm{pH}$ at the same concentration of GT in bulk, (B) the electrostatic repulsive force varies with $\mathrm{pH}$, or $(\mathrm{C})$ the conformation or steric layer thickness is altered by changing $\mathrm{pH}$. To examine these possibilities, the adsorption isotherms and the zeta potentials were determined, and PCS measurements were carried out.

\subsection{Adsorption Isotherms of GT on Latex as a Function of Solution $\mathrm{pH}$}

To examine the effect of $\mathrm{pH}$ on the amount of GT adsorbed, the adsorption isotherms were determined as a function of $\mathrm{pH}$ at various ionic strengths. Figure 5 shows that $\mathrm{pH}$ has little effect on adsorption isotherms when the ionic strength is higher than $0.085 M$.

Since electrostatic interactions among polyelectrolytes (interchain interactions) on the surface of the adsorbent are known to affect the amount of adsorption (12), this insensi-

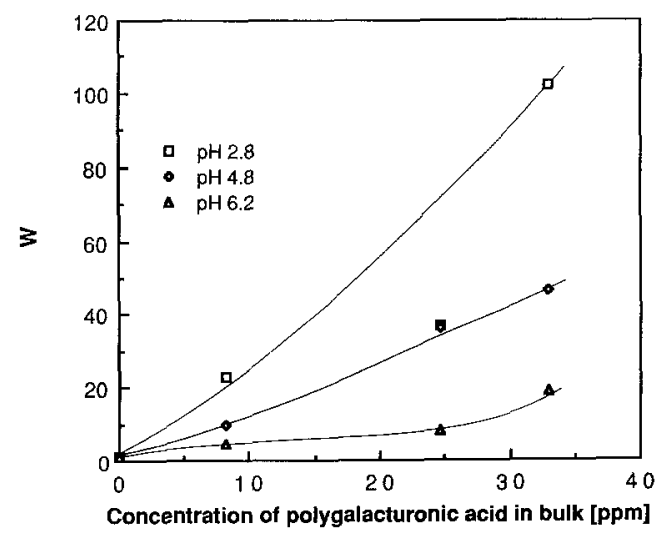

FIG. 4. Effect of $\mathrm{pH}$ on stabilization by PGUA (volume fraction $=2.6 \times 10^{-5}, \mathrm{MgCl}_{2}$ as flocculant; ionic strength: $0.33 M$ ). 


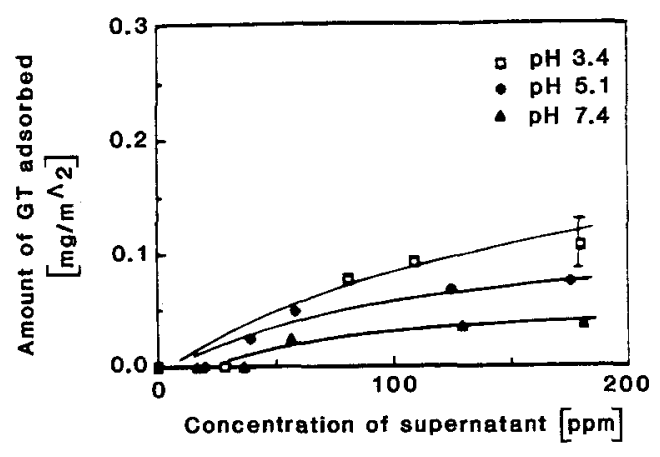

Ionic Strength; $0.01 \mathrm{M}$

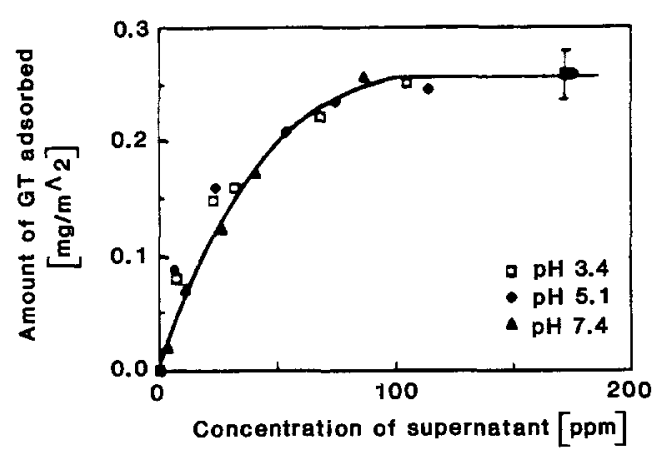

lonic Strength: $0.085 \mathrm{M}$

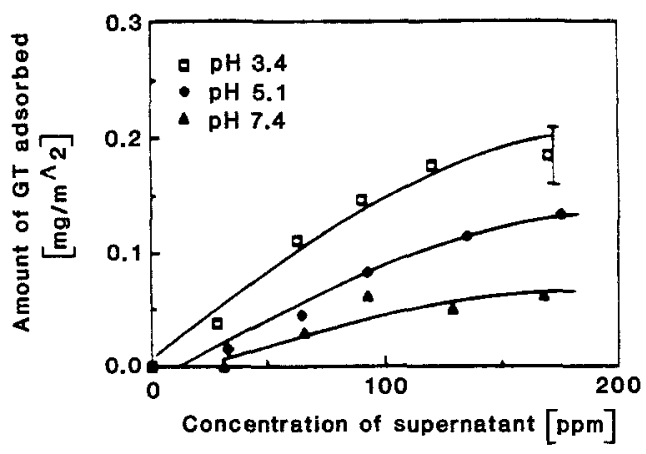

Ionic Strength: $0.06 \mathrm{M}$

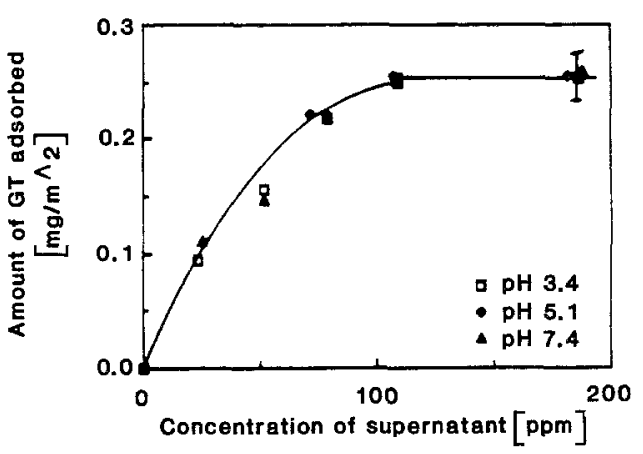

Ionic Strength: $0.5 \mathrm{M}$

FIG. 5. GT adsorption isotherms at various ionic strengths.

tivity of the amount of adsorption to $\mathrm{pH}$ variation indicates that the contribution of electrostatic interactions among polyelectrolytes to the adsorption is not significant at the ionic strengths greater than $0.085 \mathrm{M}$.

On the other hand, the adsorption isotherms at the ionic strengths of 0.01 and $0.060 \mathrm{M}$ show that the amount of adsorption depends significantly both on $\mathrm{pH}$ and the ionic strength, indicating that the variation of the electrostatic interaction with $\mathrm{pH}$ affects the amount of adsorption at the low ionic strength.

Our results differ from the results obtained by Cosgrove et al. (13) who showed that for the system of negative poly (styrene sulphonate) adsorbing on negative polystyrene latex particles, the adsorbed amount of polyelectrolyte increases with increasing ionic strength up to $\sim 1 \mathrm{M} \mathrm{NaCl}$. This difference is due to the fact that the main driving force for the adsorption is not only the electrostatic force, but also the hydrophobic interactions due to the esterified carboxyl groups in GT as shown in Fig. 1 (14). The insensitivity of the adsorbed amount to the ionic strength was also noted for the hydrophobic adsorption of proteins (15).

\subsection{Effect of $p H$ on the Electrostatic Repulsive Force}

To learn if the electrostatic repulsive force between particles varies with $\mathrm{pH}$, electrophoresis measurements were undertaken. Figure 6 shows the zeta potential is virtually independent of $\mathrm{pH}$ when the latex particles are covered with the same amount of GT $(0.25$ $\mathrm{mg} / \mathrm{m}^{2}$ ). 


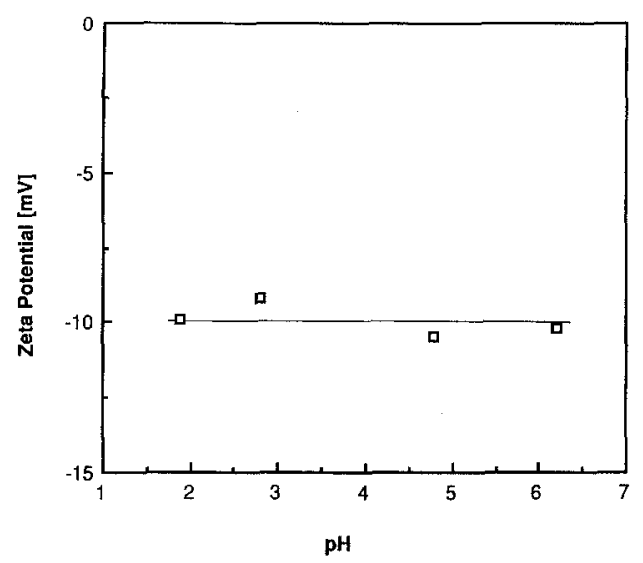

FIG. 6. Effect of $\mathrm{pH}$ on zeta potential (amount of GT adsorbed: $0.25 \mathrm{mg} / \mathrm{m}^{2}$; ionic strength: $0.33 M$ ).

The ionic strength was $0.33 M$ which corresponds to the value after the addition of magnesium chloride. This relative insensitivity of the zeta potential to $\mathrm{pH}$ variation probably results from the high ionic strength and the suppression of electrostatic interactions.

Therefore, it was found that the variation in the dimensionless stability factor with $\mathrm{pH}$ is not due to the difference in the electrostatic repulsive force between particles.

\subsection{The Effect of $p H$ on the Steric Layer Thickness}

The polystyrene latex spheres with a volume fraction of $9.4 \times 10^{-7}$ were incubated for 1 day in the GT solution (107 ppm). This concentration of GT corresponds to the saturation point of adsorption isotherms where the amount of GT adsorbed on the latex is 0.25 $\mathrm{mg} / \mathrm{m}^{2}$. The particle diameter was then measured by PCS at an ionic strength of $0.085 M$ (Fig. 7).

Figure 7 shows that the steric layer thickness is greater in solutions with a lower $\mathrm{pH}$. Since the solution contains GT molecules with highly polydisperse molecular weight, the following experiment was performed to see if the difference in thicknesses with $\mathrm{pH}$ is due to the difference in molecular size adsorbed or the difference in conformation. After the latex particles were incubated in the GT solution
(107 ppm GT, pH 7.4, ionic strength: 0.085 $M, 293 \mathrm{~K})$, the solution was centrifuged, and the supernatant with GT was decanted. The equivalent amount of buffer solution ( $\mathrm{pH} 7.4$ ) was then added. After the ultrasonication to disperse the particles at the bottom of the centrifuge tube, the $\mathrm{pH}$ was lowered to $\mathrm{pH} 2.8$ by adding $0.085 \mathrm{M} \mathrm{HCl}$, and the particle thickness was measured by PCS. The PCS data showed that the thickness increased from 16 to $70 \mathrm{~nm}$ in about $40 \mathrm{~min}$. If the molecules of different sizes were adsorbed at different $\mathrm{pH}$, this would not be observed. This indicates that the difference in the thickness with $\mathrm{pH}$ is due to the difference in the conformation of GT molecules. At a lower $\mathrm{pH}$, the ionization of carboxylic groups is repressed so that GT molecules behave like uncharged polymers, and they form loops or tails. On the other hand, at a higher $\mathrm{pH}$, since GT molecules are charged to a greater extent, the formation of loops and tails is suppressed because of strong intrachain interactions. The similar phenomena was observed by Chandar et al. (16) whose excimer fluorescence study showed that poly (acrylic acid) adsorbed on alumina takes a coiled form at a lower $\mathrm{pH}$.

The significant variation of the thickness with $\mathrm{pH}$ compared to the insensitivity of the amount of adsorption to $\mathrm{pH}$ indicates that the thickness is determined mainly by the tails, the volume fraction of which is relatively small (17). These tails belong to the main linear chains of 1,4 linked $\alpha$-D-galacturonic acid

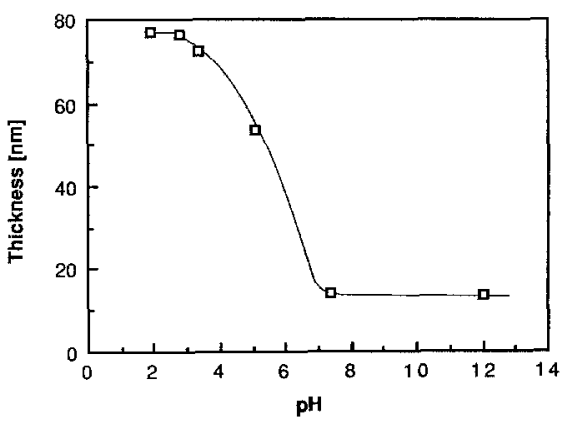

FIG. 7. Effect of pH on steric layer thickness (amount of GT adsorbed: $0.25 \mathrm{mg} / \mathrm{m}^{2}$; ionic strength: $0.085 \mathrm{M}$ ). 
since the branches are too short to give the thickness in the order of $10 \mathrm{~nm}$.

These results demonstrate that the difference in the dimensionless stability factor with various $\mathrm{pH}$ at the same amount of GT adsorbed is due to the difference in the steric layer thickness.

\subsection{Deflocculation}

In order to observe if the polystyrene latex spheres which have flocculated at higher $\mathrm{pH}$ can be redispersed by changing the conformation of GT, the $\mathrm{pH}$ of the solution was lowered. GT (29.7 ppm) was added to the buffer solution $(\mathrm{pH} \mathrm{7.4)}$ with latex spheres of the volume fraction of $2.6 \times 10^{-5}$. After 1 day incubation, magnesium chloride was added, and the turbidity was measured by the spectrophotometer. The turbidity increased as the particles flocculated and then reached a constant value after $65 \mathrm{~min}$. Next, the $\mathrm{pH}$ was then changed from 6.2 (the $\mathrm{pH}$ dropped from 7.4 to 6.2 after the addition of magnesium chloride) to 2.8 by adding hydrochloric acid solution of the same ionic strength of the latex solution $(0.33 \mathrm{M})$ and gently mixing the solution. The turbidity decreased after the addition of acid as shown in Fig. 8, indicating that the aggregates were deflocculated.

$\Delta T$ and $T_{0}$ represent the difference in turbidity and the initial turbidity, respectively.

In order to find if this flocculation-deflocculation process is reversible the following experiments were performed. GT (107 ppm) was

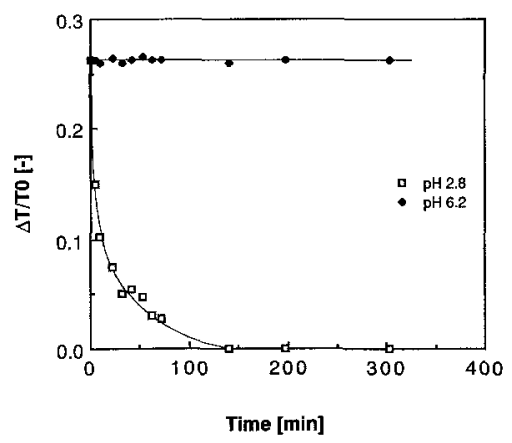

FIG. 8. The effect of change in pH on the stability.

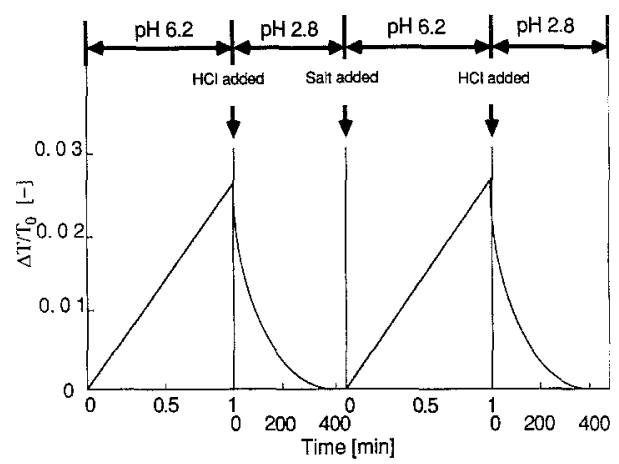

FiG. 9. Flocculation-deflocculation.

added to the buffer solution ( $\mathrm{pH} 7.4$ ) with latex spheres of the volume fraction of 2.6 $\times 10^{-5}$. After the 1 day incubation, the salt was added to induce flocculation. As shown in Fig. 9, the turbidity increased linearly with time due to the doublet formation. Then, the $\mathrm{pH}$ was changed to $\mathrm{pH} \mathrm{2.8}$. The turbidity decreased to the initial value showing that the doublets were deflocculated, and Fig. 9 shows that this flocculation-deflocculation process can be repeated back and forth.

To substantiate that the increase in the steric layer thickness causes the deflocculation, PCS study was undertaken. After the latex spheres were incubated with $107 \mathrm{ppm}$ of GT at $\mathrm{pH}$ 6.2 for 1 day at $293 \mathrm{~K}$, hydrochloric acid solution was added to lower the $\mathrm{pH}$ to 2.8 . It should be mentioned that for PCS study the salt was not added because the thickness could not be determined in the presence of aggregates. Figure 10 shows that the steric layer

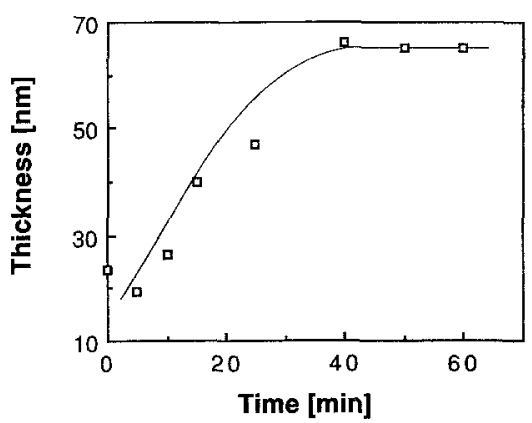

FIG. 10. The change of thickness with time. 

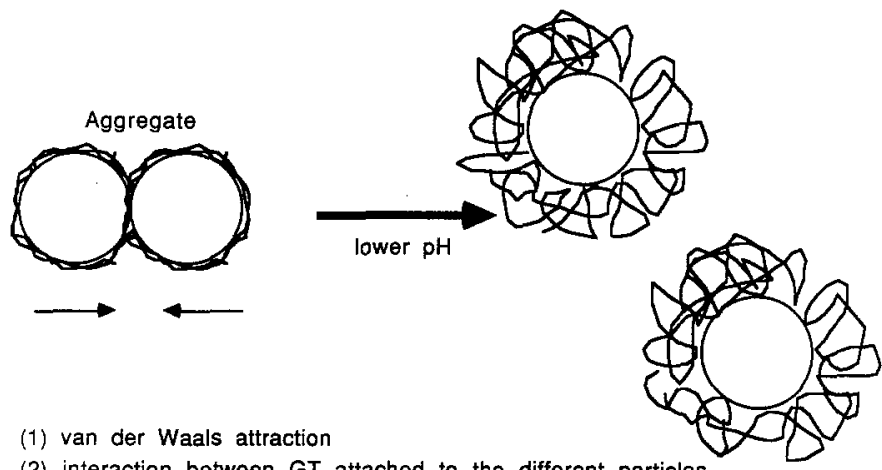

(1) van der Waals attraction

(2) interaction between GT attached to the different particles

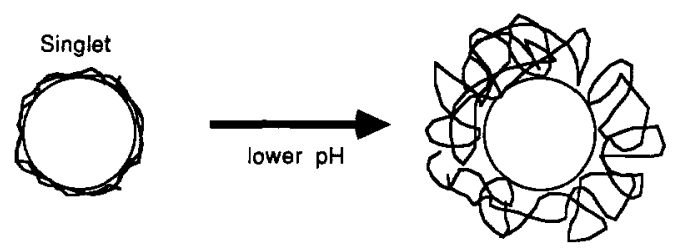

FIG. 11. Deflocculation mechanism.

thickness increases from 20 to $65 \mathrm{~nm}$ approximately $40 \mathrm{~min}$ after the $\mathrm{pH}$ was lowered, indicating that it required approximately $40 \mathrm{~min}$ for GT molecules to change the conformation.

It should be noted here that the time required for the diffusion of the hydrochloric acid into the adsorbed layer is negligible by three orders of magnitude compared to the 40 min required for this conformational change. Consequently, the deflocculation is attributed to the change in the conformation of GT with the decrease in $\mathrm{pH}$. The cause of the difference between the magnitude of the time constant for the deflocculation (100 $\mathrm{min}$ ) and the magnitude of the time constant for the conformational change ( $20 \mathrm{~min}$ ) is open to speculation. Since the flocculation studies showed that for $\mathrm{pH} 2.8$ the flocculation is negligible for the same amount of GT adsorbed as $\mathrm{pH}$ 6.2 , it is possible that the time for the deflocculation $(5 \mathrm{~h})$ corresponds to the time required for the conformation to change completely for the aggregates. The van der Waals attraction force between the particles or the strong interactions of polymers attached to the different particles, presumably make the conforma- tional change difficult in case of aggregates as shown in Fig. 11.

\section{CONCLUSIONS}

(1) Gum tragacanth is an effective stabilizer of colloidal suspensions at very low concentrations. The stabilization is a result of the steric repulsion force, and the stability can be controlled by changing $\mathrm{pH}$.

(2) At high ionic strength, the amount of GT adsorbed does not change with $\mathrm{pH}$. However, as the $\mathrm{pH}$ is lowered the steric layer thickness expands from 16 to $70 \mathrm{~nm}$. This suggests that GT changes conformation on the surface and that this conformational change is a result of the formation of loops and tails at the lower $\mathrm{pH}$.

(3) The flocculated particles can be spontaneously deflocculated by lowering $\mathrm{pH}$. The peptization is a result of the conformational change of the GT molecules on the surface, and the flocculation-deflocculation process is reversible.

\section{ACKNOWLEDGMENTS}

This work was supported by the United States Department of Energy through Grant DE-FG22-85PC80517. We 
are grateful to Prof. E. Gulari of this department for the photon correlation spectroscopy measurements.

\section{REFERENCES}

1. Tadros, T. F., in "Second European Conference on Coal Liquid Mixtures" (The Institute of Chemical Engineers, Ed.). Pergamon, New York, 1985.

2. Pfizer Inc., "Pfizer Flocon Biopolymers for Industrial Use," technical report.

3. Bergenstahl, B., Fogler, H. S., and Stenius, P., in "Gums and Stabilisers for the Food Industry 3" (G. O. Phillips, D. J. Wedlock, and P. A. Williams, Eds.), p. 285. Elsevier, New York, 1985.

4. Sandford, P. A., and Baird, J., in "The Polysaccharides" (G. O. Aspinall, Ed.), Vol. 2, p. 470. Academic Press, New York, 1983.

5. Meer, G., Meer, W. A., and Gerard, T., in "Industrial Gums" (R. L. Whisler and J. N. BeMiller, Eds.), 2nd ed., p. 291. Academic Press, New York, 1973.

6. Heath, D., and Tadros, T. F., Colloid Polymer Sci. 261, 49 (1983).

7. Stephen, A. M., in "The Polysaccharides" (G. O. Aspinall, Ed.), Vol. 2, p. 155. Academic Press, New York, 1983.

8. Aspinall, G. O., and Baillie, J., J. Chem. Soc. London, 1702 (1963).
9. Graten, N., and Karrholm, M., J. Colloid Sci. 5, 21 (1950).

10. Melik, D. H., and Fogler, H. S., J. Colloid Interface Sci. 92(1), 161 (1983).

11. Norris, J. R., and Ribbons, D. W., "Methods in Microbiology," Vol. 5B, p. 265. Academic Press, New York, 1971.

12. Lyklema, J., in "Modern Trends of Colloid Science in Chemistry and Biology" (H. F. Eicke, Eds.). Birkhaeuser, Basel, 1985.

13. Cosgrove, T., Obey, T. M., and Vincent, B., J. Colloid Interface Sci. 111(2), 409 (1986).

14. May, C. D., and Stainsby, G., in "Gums and Stabilisers for the Food Industry 3" (G. O. Phillips, D. J. Wedlock, and P. A. Williams, Eds.), p. 515. Elsevier, New York, 1986.

15. Makino, K., Ohshima, H., and Kondo, T., J. Colloid Interface Sci. 115(1), 65 (1987).

16. Chandar, P., and Somasundaran, P., Langmuir 3, 298 (1987).

17. Cosgrove, T., Vincent, B., Crowley, T. L., and Cohen Stuart, M. A., in "Polymer Adsorption and Dispersion Stability" (E. D. Goddard and B. Vincent, Eds.), Vol. 240, p. 147. Amer. Chem. Soc., Washington, DC, 1984. 